\title{
Introduction: Close and Distant Encounters with Refugees from the Ground Up
}

\author{
Kyung Hyo Chun
}

The definition of refugee status and the right to seek asylum is based on international law and the Universal Declaration of Human Rights. After the 1967 Protocol Relating to the Statues of Refugees removed the geographic and temporal restrictions of the 1951 United Nations Refugee Convention, these international conventions have been widely accepted and ratified by 147 countries (as of September 2019). While the principles were established half a century ago, the actual practice of granting refugee status has shown variability in different parts of the world, with continuous changes and transformations. Although transfigurations in the political conjuncture and changes in the implementation of international law-as well as alternating policy trends in international politicsrepresent significant contexts and undercurrents for migration and refugee studies, there are social practices which cannot be sufficiently comprehended exclusively with static insights on laws, rules, or principles.

In order to trace the dynamics on the ground, thorough description and documentation of social actions or practices is necessary not just because they form the basic building blocks of social phenomena. In the process of analyzing, such practices can emerge as rudimentary outlines for a new theoretical perspective. Even if researchers do not always name their similar approaches grounded theory generation (Glaser and Strauss 1967), this kind of heuristic openness for new viewpoints and theories is always useful for un-theorized or under-theorized phenomena, even in international relations research (Tucker 2016). In this vein, the collection of articles in this special issue focuses on the experience of refugees or asylum seekers while not losing sight of the experience of those who encounter them as locals or hosts. Indeed, by using the term "interfaces," we want to emphasize the interactional dimension of any practice, including discursive ones, taking place in the context of arrival, encounter, and 
asylum seeking.

Crossing the border and entrance procedures are the first instances of encounter that take place during the initial phases of arrival. Eunyoung Choi and Seo Yeon Park's article reflects on the arrival and entrance of Yemeni refugees into Jeju Island, South Korea in 2018, which have brought about intensive and sometimes heated discussions on migration and asylum policy in South Korea over the last two years. As Choi and Park point out, the aftermath of the refugee crisis in Europe played a significant role in manufacturing the context for the framing and interpretation of this historical event. Everyday prejudices and stereotypes about race, religion, and gender violence circulated among the South Korean population and were aggravated by the media, causing controversy surrounding refugee policy which then resulted in inconsistent policies on refugees. Voices of refugee status determination officers included in the analysis point to the multiple layers of the ground-up perspective in registering refugee issues.

Refugees often have to wait for an indefinite time period in collective accommodation and confined spaces, where routine activities are limited and therefore emotional and moral support is immensely necessary. Subin Sarah Yeo, Terese Gagnon, and Hayso Thako's article addresses the predicament of education in the context of Karen refugees on the Thailand-Myanmar border. Through an ethnographic case study in the Mae La refugee camp, it reveals thatfrom overlapping sources of authority with divergent visions about the future of refugee learners - the existential crisis of being members of a stateless nation is the most pressing matter for education to address. Drawing on theories of pedagogy of liberation and grassroots development, the article predicts that the latest trend in refugee education will ultimately fall short of being liberating for refugee students, as it keeps existing power structures intact without addressing fundamental questions about to what ends education is practiced.

Even when refugees are starting to settle and live among the local population, arrival is still on-going. Dong Ju Kim's research looks at civic responses to the refugee crisis after 2015 in a German city, focusing on a pop-up café where locals and refugees have a chance to meet casually. Initiated by church organizations for humanitarian and social aid, there are no other explicit goals or purposes of this project café except for providing a place for interaction and conversation to ensure a "proper arrival." While participating as a volunteer in this café, Kim asks what kinds of expectations accompany the participation of volunteers as hosts and refugees or visitors as guests. Reflecting on Derrida's deconstruction of the idea of hospitality, he highlights the practical logic of hospitality on the ground using ethnographic observations and interviews with volunteers and refugees at the café. He suggests that a practice approach to hospitality as a process is necessary and only such an approach can provide a proper understanding of the widely appropriated notion of hospitality-as a European value or as a value 
characteristic of a certain religion.

During this whole multi-staged process of arrival, group characteristics of refugees are perceived within the domestic political context, and in comparison with other immigrant groups. Michał Buchowski’s study describes and analyzes the contrasting attitudes of Poles towards absent Muslim refugees and physically present Ukrainian labor immigrants. Both groups have been historically seen as "significant others" perilous to the nation, but the perception of them is entirely different today. Muslims are rejected while Ukrainians' presence is accepted. The ethnic, linguistic, and religious super-homogeneous character of Polish society affects the perception of Muslim immigrants, who were cynically rejected by the right-wing populist authorities during the refugee crisis in 2015. In contrast, economic logic and necessity justifies acceptance of Ukrainians as they are considered culturally and "racially" close. Based on this contrast, Buchowski argues that within the category of significant others, a differentiation between distant/absent/hostile and familiar/present/tolerated significant others should be made.

Group characteristics and related stereotypes and prejudices are enhanced by the media and reproduced while in circulation. Kyung Hyo Chun's article looks into how media representations of North Korean defectors reproduce the images of North Korean defectors, while paying particular attention to the contrasting voices of the North Korean defectors themselves. As a pilot study, this article employs interviews with four North Korean defectors to address the gap between media representation and self-presentation. The self-presentation of North Korean defectors reveals that they are eager to be in charge of constructing and controlling their own images, which goes beyond hitherto nationalized, gendered, and ethnicized identities. Self-presentation, at the same time, is a product of strategic choices conditioned by social discourse and media representation. Interviewees portray themselves as opposed to the negative images of North Korean defectors which have been circulated and consumed by the media. Such self-presentation reveals dissonance between the conscious and the unconscious, public and personal, and front stage and back stage.

Each account in this special issue sheds light on a different interface and reveals the multifaceted nature of border-crossings and encounters. This multiplicity does not simply originate from the sheer number of social groups or parties engaged in this encounter, but reflects the complexity of practice, experience, and social categorization, as well as the numerous phases in the temporal process of dwelling while moving. When dealing with this complex multiplicity, only a ground-up approach will enable us not to lose sight of the fact that abstractions such as borders, sovereignty, and legal norms only take shape in everyday practice. 


\title{
References
}

Glaser, Barney G., and Anselm L. Strauss. 1967. The Discovery of Grounded Theory: Strategies for Qualitative Research. Chicago: Aldine.

Tucker, Todd N. 2016. "Grounded Theory Generation: A Tool for Transparent Concept Development." International Studies Perspectives 17 (4): 426-38.

\begin{abstract}
Kyung Hyo Chun is a Senior Researcher at the Institute for Peace and Unification Studies (IPUS) at Seoul National University. Before joining the IPUS, she was a Postdoctoral Researcher at the Academy of East Asian Studies, Sungkyunkwan University and a HK Research Professor at the Institute of Humanities for Unification at Konkuk University. She served as Managing Editor for the S/N Korean Humanities from 2015-2016 and is currently Managing Editor for Scopus-indexed Asian Journal of Peacebuilding (AJP). Chun completed her BA (anthropology) at Seoul National University, and MA (anthropology with museum training concentration) at the George Washington University in Washington, D.C. She earned her doctorate in anthropology from the University of British Columbia, Canada. Her areas of research interest include post-coloniality, nationalist discourse, North Korean refugees, commemorations, museum representations, material culture, cultural properties, multiculturalism, and media politics. Email: anth.chun@gmail.com.
\end{abstract}

Submitted: April 16, 2020; Accepted: April 27, 2020 